\title{
The Next Generation \\ PROVIDING INSPIRATION AND TRAINING FOR FUTURE MARINE SCIENTISTS
}

\author{
BY VIKKI GUNN AND LAURENZ THOMSEN
}

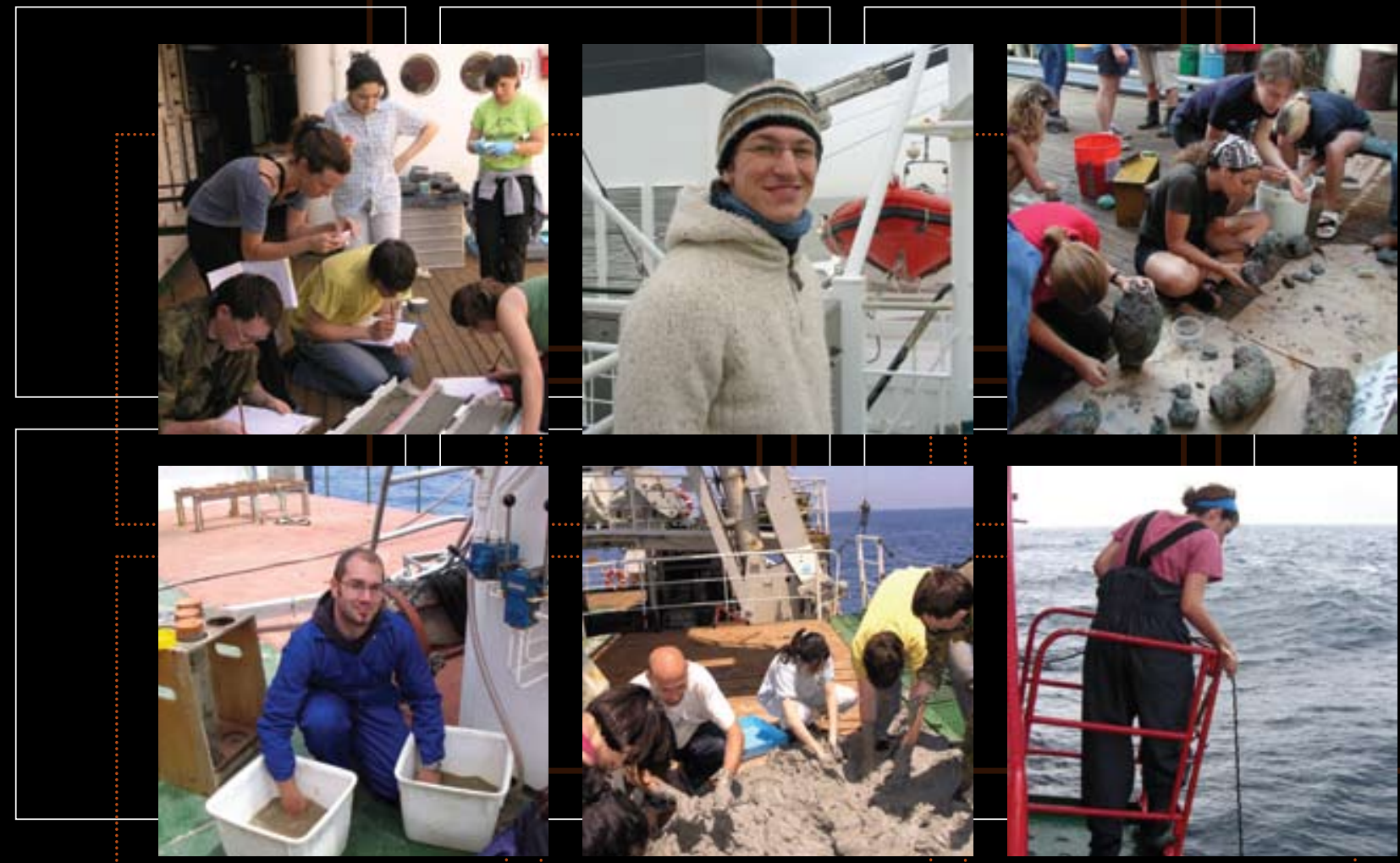

ABSTRACT. An integral part of the HERMES project was a comprehensive training and outreach program, designed to engage a wide spectrum of audiences on issues and topics related to the deep-sea environment. Using the latest in Web-based technology alongside more conventional approaches, a series of initiatives and activities resulted in the development of resources aimed at school children, the general public, graduate students, the industrial sector, and policymakers. Innovative and engaging learning tools targeted at specific audiences have opened up the world of deep-sea research, providing essential information and facts in an easily digested format. HERMES has supported over 100 postgraduate students, either through direct financial support or provision of data. The project has also supplied hands-on training aboard research vessels, opportunities for young scientists to work at other partner institutions, and the valuable experience of working within a multi- and interdisciplinary project that aimed to address some of the biggest questions and threats to our deep-sea environment. 


\section{INTRODUCTION}

A vital objective of the HERMES project was to educate and enthuse a wide range of people about the value of the offshore environment and the importance of using its resources in a sustainable and responsible manner. Raising awareness of such issues helps the public understand and support governmental decisions related to management of Earth's resources.

But why should the public bother with HERMES? What has changed since the appearance of a cartoon in The New Yorker in the 1980s reflecting the thenpopular opinion, "I don't know why I don't care about the ocean, but I don't?"

Some important developments have changed this attitude, not least of which is the general increase in interest in global environmental issues. More specifically, established industries, such as fisheries and hydrocarbon extraction, are moving rapidly and steadily into deeper waters as shallower and more accessible resources become depleted. Deep-water oil and gas reserves and fishing stocks that were once uneconomical to exploit now present viable opportunities for these industries. Indeed, deep-sea fishing and hydrocarbon extraction now routinely occur in water depths of more than $1500 \mathrm{~m}$ and $2000 \mathrm{~m}$, respectively, and will continue to expand over the coming 20 years as higher prices and technological advances combine with dwindling reserves to make deeper exploitation an economic option. As this expansion occurs, science and industry need to combine efforts to increase understanding of ocean margin ecosystems to ensure their sustainable management, and this knowledge must be made available to researchers, educators,

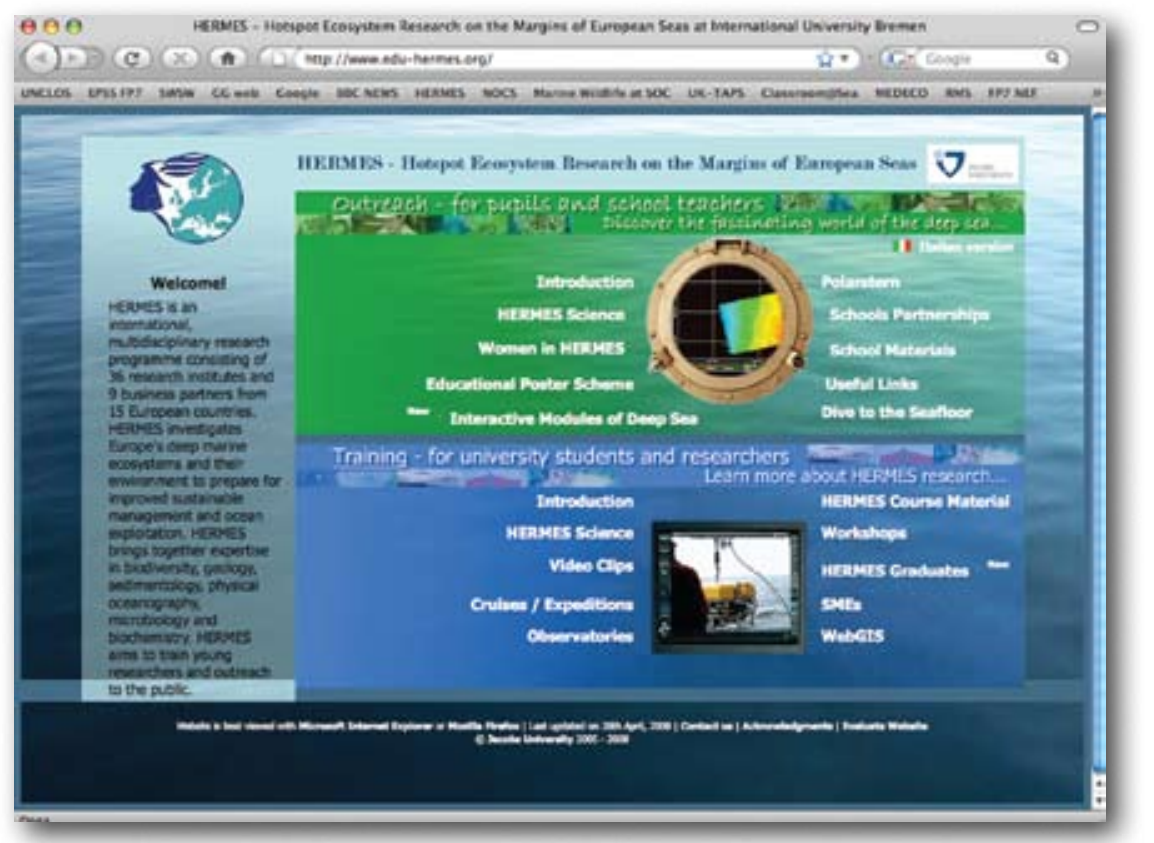

Figure 1. The HERMES education and outreach Web site (http://www.edu-hermes.org) provides resources and information for a range of audiences, from school children to HERMES postgraduate students.

teachers, policymakers, nongovernmental environmental organizations, and governments. Critical to successful resource management is a new generation of well-educated specialists for whom a multidisciplinary, ecosystembased approach to understanding our ocean is second nature.

A dedicated training and outreach program for a range of age groups, from school children, to university students, to young researchers, to industry employees, was developed to support the HERMES commitment to train future marine scientists from Europe and elsewhere. HERMES designed a series of activities and products to enhance public awareness of ocean margin ecosystems, with special emphasis on the study of ocean margin habitats and the interaction of the biosphere and geosphere. Central to the success of this project was the identification of various target audiences and their specific needs, developing ambitious but realistic goals, and involving professionals with scientific and pedagogic expertise in the creation of products appropriate for the end user.

\section{MARINE SCIENCE IN CYBERSPACE}

As a means to reach the broadest audience possible, geographically and demographically, much of the outreach program centered around providing resources to schools via a dedicated Web site (http://www.edu-hermes.org; Figure 1). Since its launch in July 2005, the site has received over 100,000 visitors. Although intended to be accessible to all audience levels, the resources presented here are specifically tailored to 11-16 year-old pupils and their teachers, and include class materials, access to interactive self-education modules, profiles of project students working on 


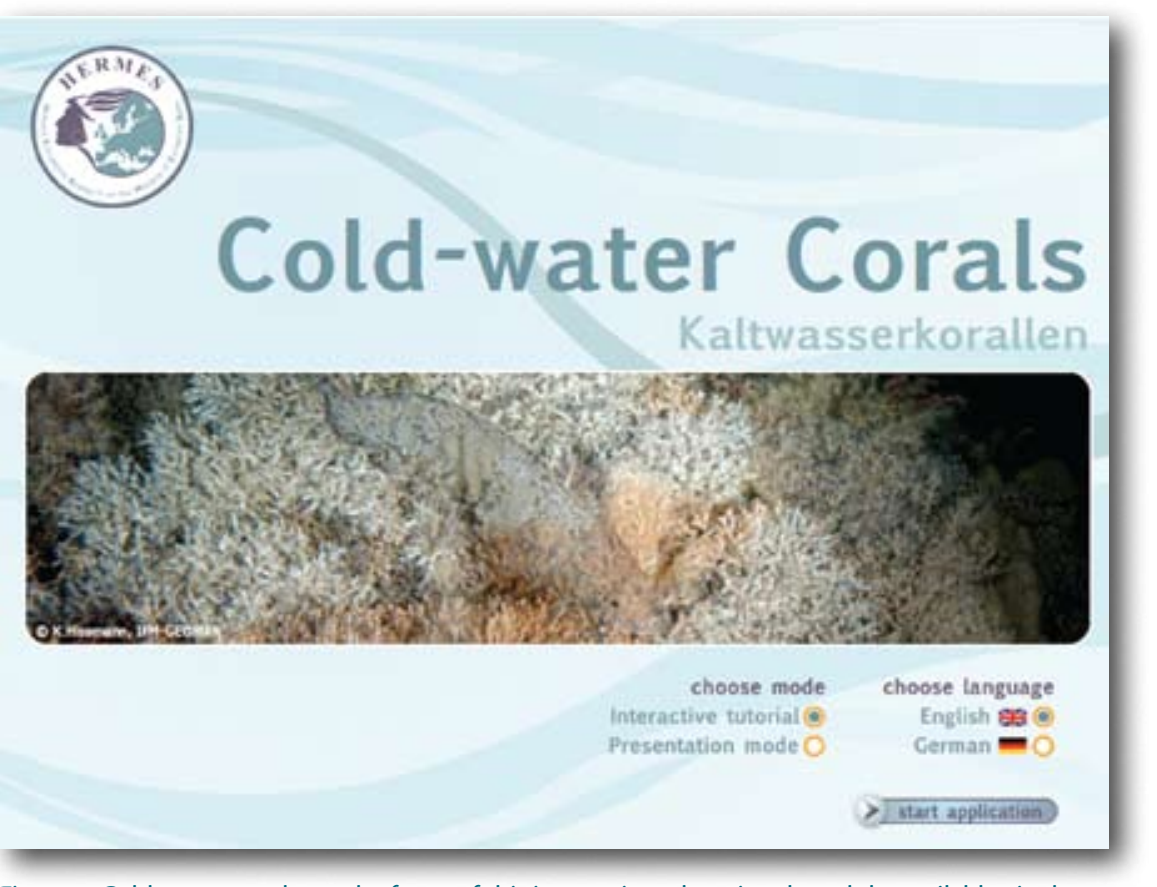

Figure 2. Cold-water corals are the focus of this interactive educational module, available via the HERMES outreach Web site (http://www.edu-hermes.org/interactive/Coldwater_Corals).

HERMES research, links to school partnership programs, and "live" blogs from scientists working on research vessels.

Additionally, a separate area of the Web site targeting undergraduates and postgraduate students was set up to provide access to more advanced scientific information about HERMES topics, important HERMES publications, career advice, general information about scientific good practice, and video footage from field experiments and research expeditions. Additionally, HERMES has established its own

Vikki Gunn (vkg@noc.soton.ac.uk) is HERMES Project Manager, National Oceanography Centre, University of Southampton, Southampton, UK. Laurenz Thomsen is Professor of Geosciences, School of Engineering and Science, Jacobs University Bremen, Bremen, Germany.
YouTube channel (http://www.youtube. com/HERMESproject), which provides a public gateway to video footage from remotely operated vehicle (ROV) and lander deployments-materials that would otherwise not be easily accessible outside the scientific community.

\section{INTERACTIVITY: THE KEY TO ENGAGEMENT}

Three interactive educational modules are key features of the online educational resources provided by HERMES. The first was developed by one of HERMES' small business partners, MMCD, in collaboration with the project's coldwater corals experts. This module allows the user to progress through a series of "chapters" to learn about the distribution, life cycle, discovery, and exploration of cold-water corals and the threats they face (Figure 2). The module can be used either in interactive mode-where narrative and on-screen text, combined with puzzles, activities, and quizzes, guide the user through the various units-or in presentation mode, which is suitable for broadcasting to a group of students. The second module, developed at Jacobs University Bremen, takes a similar approach with submarine canyons, and includes case studies of the most recent scientific advances achieved within HERMES. The most recent addition to the interactive educational resources is an introduction to Geographic Information Systems (GIS) and their use in scientific research-a tool that has proved to be an important feature in HERMES' success.

Visualization of complex scientific concepts and processes is a specialty of another of the HERMES small business partners, ArchimediX. Working alongside experts in cold seep and mud volcano studies throughout the project, they developed a fully interactive DVD that enables the user to visualize the processes involved in mud volcano evolution by using a combination of high-tech graphics and real ROV footage to create a realistic impression of the seafloor environment in areas of seep activity (see Box 1 and Figure 3 for more detail).

ArchimediX also prides itself on introducing new forms of presentation into scientific work. In the course of a highly acclaimed collaboration with the Zurich University of the Arts, a variety of diverse approaches led to new methods of visualizing the focal points of various fields of research. For the HERMES project, it has yielded some beautiful artwork (see cover image of this issue) and a new synergy between the sciences and the arts-a link that could prove vital in engaging all sectors of society in marine issues. 
PUTTING REAL MARINE

\section{SCIENCE INTO CLASSROOMS}

A novel aspect of the HERMES outreach

Web site that is particularly popular with schools is the "live" coverage of research expeditions. On a number of occasions, HERMES partners provided coverage of their research activities at sea via daily blogs written by scientists, research students, teachers, or pupils on board a research vessel. The Classroom@Sea initiative (http://www.classroomatsea. net; Figure 4), run by the National Oceanography Centre, Southampton (UK), placed two schoolteachers on each of the three legs of a cruise aboard
RRS James Cook over a six-week period in summer 2007 to bridge the gap between marine science research and the classroom. The teachers worked as part of the HERMES scientific team (Figure 5) and relayed their experiences back to schools across Europe via the Classroom@Sea Web site. In a similar

\section{Box 1. The Art of Visualization}

Since 2000, members of the team at ArchimediX have established themselves in the European market as specialists in visualization and presentation. As one of the leading enterprises in this field, ArchimediX's focus lies in the digital reconstruction and presentation of historic buildings that no longer exist, such as the Emperor Thermae at Trèves or Charlemagne's imperial palace, known as the "Pfalz," near the Rhine River.

Participation in the HERMES research project gave ArchimediX owners Philipp Möckl and Reinhard Munzel the opportunity to add a dynamic aspect to their established field of work. The challenge was to translate abstract facts into pictures and-across the boundaries of scale-to illustrate both very fast developments as well as processes that occur over long time periods. Mud volcanoes and their evolution was chosen as a focus for this particular challenge.

Communication with HERMES scientists formed an essential part of this work-the final product depended on their data and research results. Almost automatically, the major part of the work to be done shifted toward the end of the research project, as it is only then that results become available to be rendered into visible form.

There is a need to continually develop new presentation techniques in order to offer onlookers images that can be grasped easily. A good example of this aspect is the presentation of mud volcanoes that, with dimensions of up to $2 \mathrm{~km}$, could not be captured photographically because of their scale and the unfavorable light conditions under water. Thus, a naturalistic image had to be ruled out.

A mere graphic rendering, however, would not have done justice to the submarine landscape. Hence, ArchimediX chose a form of presentation that approximates the visual aesthetics of filmed underwater footage, which helps retain the atmospheric character of this unique environment. Another task for ArchimediX was to embed the results into a vivid presentation context that would be both understandable and interesting to a wide range of audiences: the researchers involved in the project, the experts, and the interested public. Based on this approach, the idea of an interactive presentation was developed that would comprise both a collection of PDF files containing scientific publications as well as a module that invites visitors to intuitively explore the main points of the research work. In a fanciful contraption dubbed the "Mud Taxi" - a hybrid of submarine and UFO-the underwater world can be explored in various dimensions. Numerous switches and levers invite visitors to try them out and play. On this platform, research work and results can be presented impressively in an entertaining and light-hearted way. This interactive learning experience is available on DVD. 


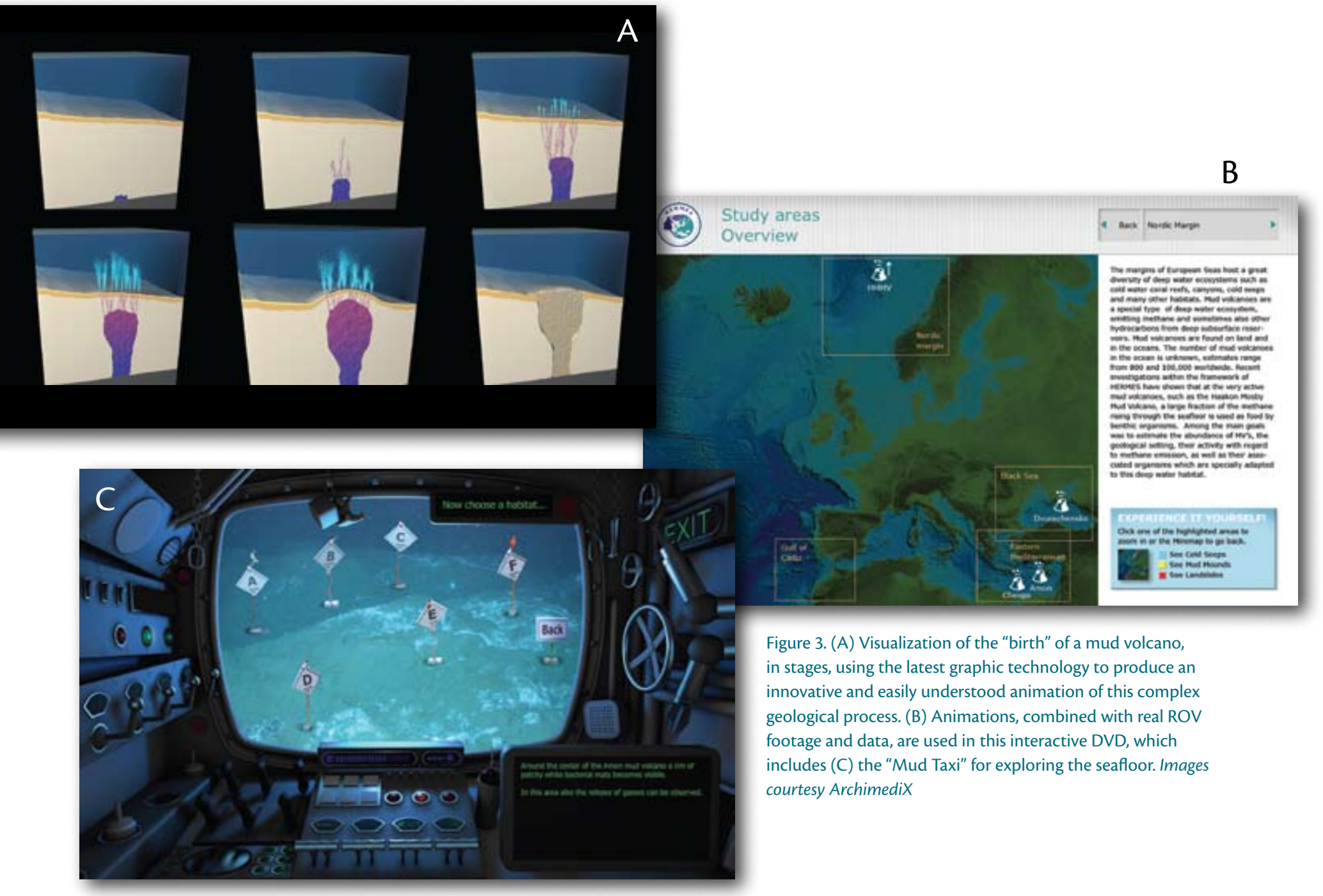

vein, Jacobs University Bremen took the ambitious step of involving both teachers and pupils on one leg of an International Polar Year cruise aboard RV Polarstern in early summer 2007. Both cruises provided a novel means for schoolchildren and the public to see how real marine science research is carried out, with all of its challenges, successes, and disappointments. Use of a variety of media, from blogging, to video clips, to ROV footage, to live Web cams, enabled the experience to be brought into the classroom more vividly than ever before. Exposure to this cutting-edge marine science was reinforced by implementation of educatorscientist partnerships, where HERMES scientists visited their partner schools at least twice a year to excite school children about the ocean. These activities have introduced the multidisciplinary nature of marine science at an early stage of general education to help to stop, and hopefully reverse, the declining interest in science, and perhaps inspire pupils to consider marine science as a career.

\section{HANDS-ON TRAINING FOR HANDS-ON CAREERS}

The HERMES approach to training for young marine scientists revolves around the multidisciplinary approach that has been key to the success of the project as a whole (see Boxes 2-5). A series of workshops specifically designed for HERMES students and postdoctoral researchers (but often gate-crashed by more senior scientists!) aimed to provide solid, cross-disciplinary background knowledge of the main strands of HERMES research. Consequently, marine biologists learned about the geology of submarine canyons, geophysicists were enlightened about deep-sea ecology, and sedimentologists learned to appreciate the finer points of cold seep biogeochemistry. A popular part of this training proved to be the ocean governance and policy development lectures, which provided many students with their first exposures to the very 
real application of scientific results and how their work can make a difference to society. In addition, a number of training classes in more practical applications, such as the use of GIS, interaction with the media, and job interview techniques, have helped to arm HERMES graduates with the tools they will need in their future careers as marine scientists.

On a more practical level, HERMES also contributed to providing some 80 graduate students from around Europe with hands-on practical training

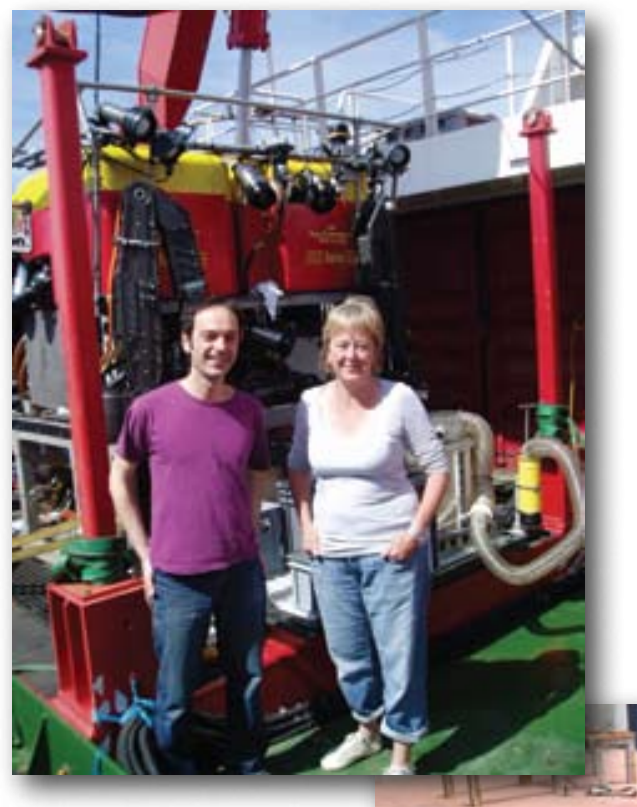

Figure 5. School teachers Eduard Vives and Gillian McGahan pose next to ROV Isis aboard RRS James Cook during the first leg of the JC10 cruise in summer 2007, and school teacher Richard Ingram gets his hands dirty on Leg 3 of the same cruise.

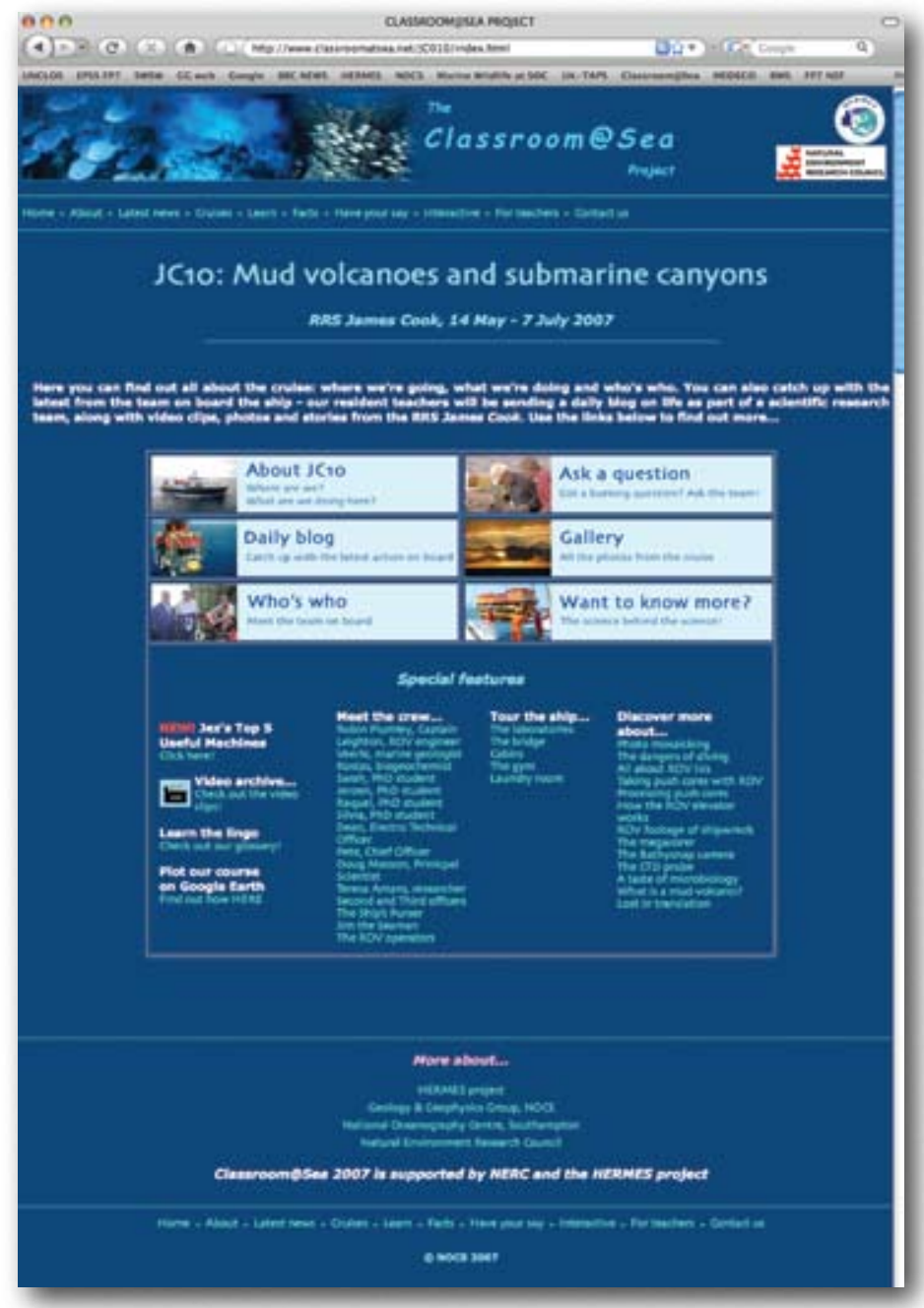

Figure 4.Classroom@Sea provides an opportunity for school children and the general public to follow the progress of marine science research expeditions around the world's ocean. The Web site has followed the progress of three HERMES cruises, including a major cruise in 2007 in which six school teachers participated as part of the science team. 


\section{Box 2. Jeroen Ingels, Universiteit Gent, Belgium}

I am a fourth-year PhD student in the Department of Marine Biology at Universiteit Gent, Belgium. I received my master's degree in biology at Universiteit Gent, during which I completed a one-year thesis in the field of archaeozoology. However, I was keen to learn more about the marine environment and its mysteries - a world I had already encountered a few times during my biology education. Following an MSc in marine and lacustrine sciences, also at Universiteit Gent, I was instantly enchanted by the world of meiofauna (benthic animals in the size range of 32-1000 $\mu \mathrm{m}$ ) and all its peculiarities, and decided I wanted to learn more on this subject. I was offered the unique opportunity to work on the HERMES project as a PhD student; as an enthusiastic and determinately curious novice, I was pleased to become part of the multidisciplinary HERMES community.

The aspects in the HERMES work program covered by my research are those dealing with slopes and submarine canyons along the European continental margins. The animals I am specifically interested in are the free-living marine nematodes-microscopic worms living in marine

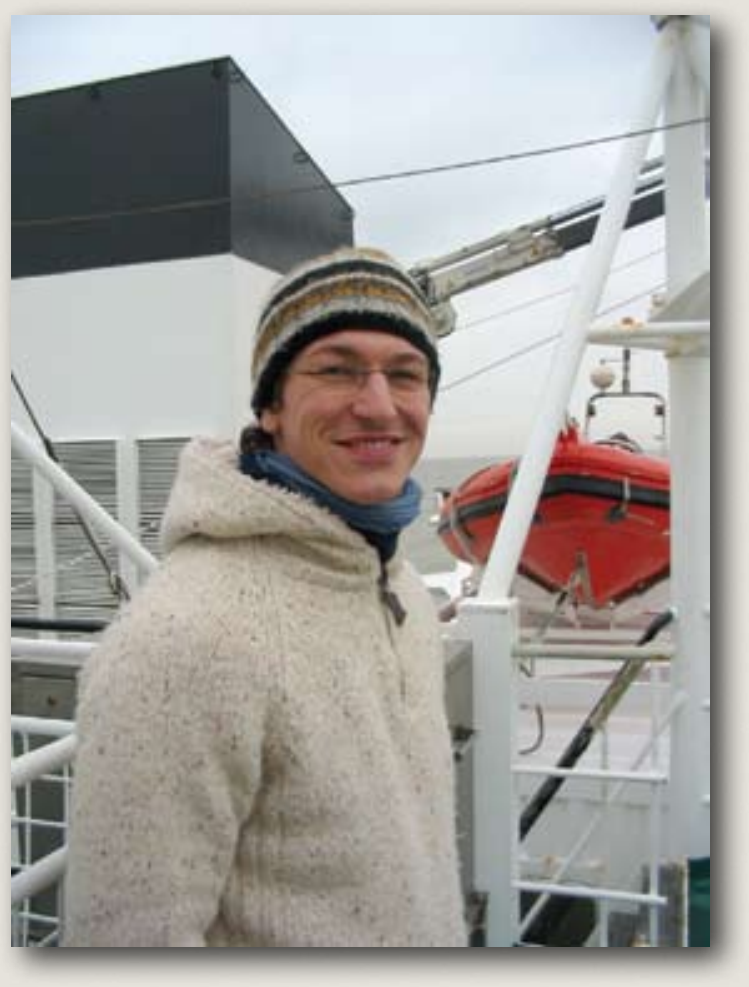
sediments. Even very small sediment samples usually contain huge numbers of these tiny creatures. The Marine Biology Lab in Gent is renowned for nematode research and offers good facilities, making it an ideal workplace. Of course, before studying the nematodes you have to get your hands on them! That is why an international and multidisciplinary project like HERMES provides the ideal platform to participate in deep-sea cruises with the latest surveying and sampling technology onboard, such as ROVs, to collect samples. Four cruises and many weeks at sea in collaboration with numerous HERMES partners enabled me to collect an extensive set of samples from various regions. My research aims are to assess nematode biodiversity in submarine canyons and investigate what drives and maintains this diversity. Furthermore, I am investigating the position of nematodes in the deep-sea food web by means of natural observation, and in vitro and in situ experiments. By addition of ${ }^{13} \mathrm{C}$-labeled food to the community, we are trying to unravel nematode feeding patterns in submarine canyons and identify ecosystem processes in these environments. The Nazaré Canyon is of particular interest to this research because although it has no direct riverine input, it acts as a huge trap for organic material. Due to the very high influx of this material, it is possible that the nematode communities in the canyon behave differently from communities in other types of environments.

Working within the HERMES project and participating in its many cruises, conferences, and workshops gave me not only the necessary material to conduct my research but also a great deal of life experience and contacts within the marine scientific community. The HERMES project strongly supports events where young students are encouraged to get involved in a variety of scientific activities, thus providing training that enhances their future prospects. The complete and direct integration of young scientists into the community is undoubtedly a good thing, not only for the scientific community but also for everyone who benefits from its results and breakthroughs. Integrating training into research-a successful aspect of the HERMES project-is invaluable because it provides experience and knowledge to the next generation of scientists and creates a transition for those young people who will eventually stand in the shoes of today's experts. 


\section{Box 3. Stefanie Grünke, Max Planck Institute for Microbiology, Germany}

I am a third-year PhD student at the Max Planck Institute for Marine Microbiology in Bremen, Germany. My main focus is analyzing the morphological and 16S rRNA gene-based diversity of giant sulfide-oxidizing bacteria at cold seeps along the European margin. Cold seeps are sites of active gas, fluid, or mud discharge. They are characterized by emissions of hydrogen sulfide, methane, and hydrocarbon-rich fluids. At many cold seeps, giant mat-forming bacteria, such as the filamentous Beggiatoa and the spherical "sulfur pearl" Thiomargarita, have been observed. These bacteria thrive at the oxic/anoxic sediment interface, where they oxidize the energy-rich substrate sulfide to elemental sulfur by using either oxygen or nitrate. The elemental sulfur is stored inside the cells, and is the reason for the conspicuous white appearance of the sulfide-oxidizing bacteria on the seafloor.

Within the HERMES program I had the opportunity to study microbial "hotspots" of mat-forming sulfide oxidizers along the European margin, including the Håkon Mosby mud volcano off Norway and the Amon mud volcano off Egypt. We discovered gigantic Beggiatoa mats covering an area of more than $800 \mathrm{~m}^{2}$ at the Håkon Mosby mud volcano, mainly comprised of filaments with a diameter of less than $20 \mu \mathrm{m}$. In contrast, we observed very thin and almost invisible mats of Beggiatoa at the Amon mud volcano, with filament diameters $>100 \mu \mathrm{m}$. In addition, we also found Thiomargarita sp.-resembling bacteria at the Amon mud volcano, making it the third known habitat of these extraordinary organisms worldwide.

As a HERMES participant, I had the opportunity to take part in the BIONIL and PSARKXXII-1b expeditions and personally collect the samples needed for my diversity study. What I liked most about theses cruises was being able to interact with scientists from all over Europe, and being able to exchange ideas and develop concepts and strategies for a comprehensive analysis of cold seeps. This experience was further strengthened during the annual HERMES science meetings and workshops where I met many new and young scientists. Learning about the different hotspot ecosystems studied within HERMES and the research progress in those areas, as well as understanding the whole concept of science, policy, and social interaction, has been inspiring for me personally and for my future scientific career.

The HERMES program and its organizers provided me with everything a young scientist could wish for: the opportunity to learn and understand concepts of various scientific fields, the chance for comprehensive work on exclusive samples, meeting and discussing new ideas with other PhD students and experienced researchers, and just getting to know nice people from all over Europe. 


\section{Box 4. Catalina Pascual, University of Barcelona, Spain}

I am from Manacor (Majorca, Spain). After completing a master's degree in environmental science, I started my PhD in the marine science research group (Grup de Reserca Consolidat en Geociències Marines [GRC-GM]) at the University of Barcelona. Within the HERMES project, my work focuses on the relationship between sedimentary processes and the biogeochemistry of particulate matter in submarine canyons of the Northwest Mediterranean. I aim to identify the main processes that drive particle fluxes in canyons and on open slopes by studying the sediment's biogeochemical characteristics and their relationship to the amount and quality of particulate organic matter, as it is thought to be an important source of energy for deep basin ecosystems.

By analyzing the main composition of the settled material-organic matter, calcium carbonate, opal, and lithogenic fractions - I hope to identify trends in their spatial and temporal variability and learn how they relate to the processes that drive fluxes. I am also determining the grain size distribution, which provides useful information about the intensity of the physical processes. Furthermore, I am analyzing the pigment and amino acid content of the sediment, which indicates organic matter sources, degradation state, and hence its bioavailability for the benthic communities.

During my time with the HERMES project I have had the opportunity to work with sediment trap samples recovered from the Cap de Creus and Lacaze-Duthiers submarine canyons during a dense shelf water cascading event (see Canals et al., this issue). Such energetic events are of special importance because they provide express transport of material to the deep basin. The multifaceted character of HERMES has provided me with an invaluable, complete data set for the accurate description of such a powerful event.

HERMES has given to me the opportunity to participate in sampling cruises and witness my sampling bottles returning from the seafloor filled with material from the cascading event-the chance to share that moment with fellow researchers was very exciting. The HERMES annual science meetings have provided huge motivation-not only due to the vast quantity of exciting new work presented by the various research teams and the friendly relationship among scientists from all over Europe, but also through exposure to the socio-economic applications of the project (education and policy), which reinforces the reasons for pursuing a career in research. The HERMES project has definitely had a positive influence on my research career by enabling me to closely collaborate with fellow scientists in a European framework. 


\section{Box 5. Autun Pursur, Jacobs University Bremen, Germany}

I completed a master's degree in oceanography at the National Oceanography Centre, Southampton (UK) during the first year of the HERMES project. Soon after that, an interesting HERMES PhD position came up at Jacobs University Bremen in Germany, and I took it.

During my three-year $\mathrm{PhD} \mathrm{I}$ am studying the susceptibility of one of the more unusual European marine organisms to various types of environmental stress. The organism is Lophelia pertusa, a deep-water coral living predominantly at depths in excess of

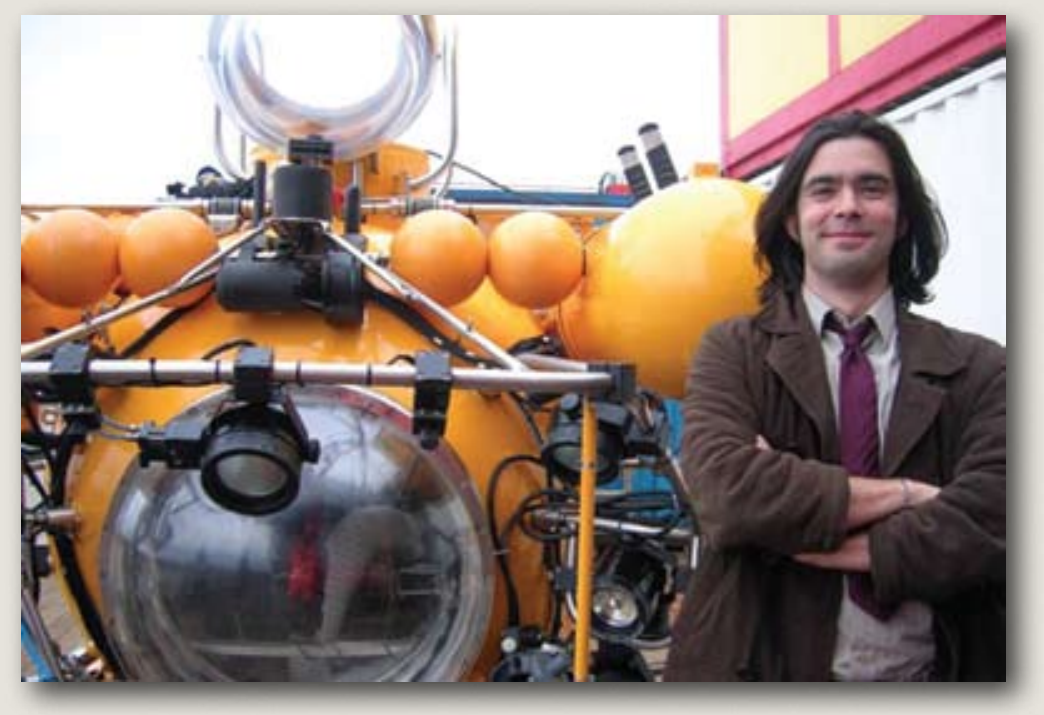
$100 \mathrm{~m}$ throughout the European seas.

The coral forms complex three-dimensional stony reef structures with growth much like tropical corals. There are indications that these structures produce many habitat niches for other organisms (including commercial fish), and are islands of increased biodiversity in the deep sea. Through advances in surveying technology, an increasing number of these reefs are being discovered. In my work, I am trying to develop novel techniques to monitor perturbations in environmental parameters at reef sites and gauge the likely threat human activity might have on these organisms. The increased abundance of fish stocks in reef regions has made them susceptible to fishery impact, and although direct trawling of reef sites is becoming prohibited at increasing numbers of sites across Europe, the potential impact of suspended sediment disturbed by nearby trawls on reef health has not been adequately assessed. Another potential threat to reef health is that posed by the offshore oil and gas industry. Some of Europe's richest and most extensive deep-water reefs are found in regions appealing to this industry, and the potential impact of the waste material from drilling (mainly rock chips) that are routinely discharged at sea may have a negative impact on reef health. One of my objectives is to gauge the actual risk posed by these activities.

Working within the HERMES community has been a great help in my development as a research scientist. Contacts made with other young scientists at HERMES meetings and training workshops have developed into collaborations, often in unexpected directions not related to my initial studies. During my own research, I have also been able to collect geological and various genetic samples to support the work of other HERMES community members.

Another big advantage has been acquiring useful cruise time and scientific infrastructure through HERMES institutes. Small institutes like Jacobs University Bremen seldom have access to research vessels or large amounts of equipment, but within the HERMES community both have been available to me. Through the HERMES project, I have benefited from a cruise aboard RV Polarstern to the Arctic (with a dive in the JAGO manned submarine!) and from extensive use of temperature-controlled experimental laboratories at University of Gothenburg, Sweden. We have, in turn, made our large seawater equipment testing facilities and large flumes available to other HERMES members, which has resulted in fruitful collaborations.

Personal contacts with so many scientists from European institutes at HERMES meetings have greatly aided my $\mathrm{PhD}$ work, both through access to infrastructure and in development of ideas. 

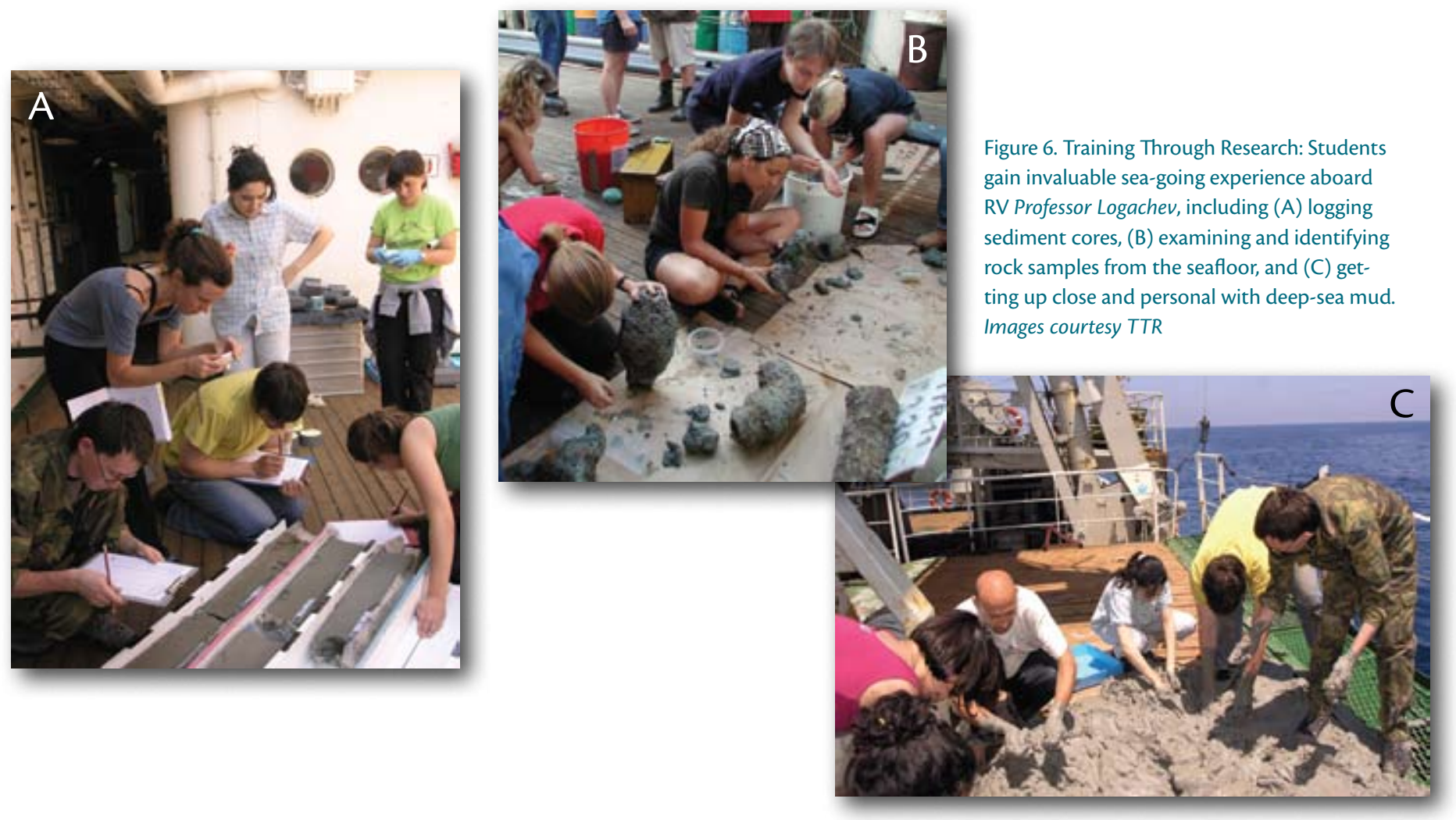

marine science, covering the full spectrum of deep-sea processes, from tectonics to physical oceanography.

By being part of the HERMES partnership, postgraduate students and young researchers also had unprecedented opportunities to join mainstream HERMES research cruises in order to carry out experiments and gather data necessary for their research, or purely to gain valuable practical experience. By doing so, they not only had access to the latest technology and techniques but also the opportunity to work within a multidisciplinary team comprising some of Europe's leading marine scientists. The overall aim of the HERMES training program was to create a dynamic and stimulating environment in which young researchers could (1) flourish through close and productive collaboration with researchers from different institutes across Europe, (2) participate in a wide range of project activities and events, and (3) feel they are an integral and essential part of the HERMES research team.

\section{SPREADING THE WORD: HERMES IN THE EYE OF THE MEDIA}

Some measure of the success of a project can be taken from the amount of media attention it attracts. During its lifetime (and at the time of writing this article), HERMES has so far contributed to or produced $15 \mathrm{TV}$ documentaries broadcast on mainstream television channels, more than 35 TV news features, $100+$ articles in national newspapers, 16 feature articles in magazines, and more than 20 radio interviews. HERMES has been featured in deep-sea exhibitions in public museums, and HERMES scientists have participated in national science festivals, presented public lectures, and provided themed posters free of charge to schools and educational organizations. Perhaps the most impressive figures are those related to the students who have been supported by HERMES funding or benefited from data generated by HERMES research: more than $100 \mathrm{PhD}$ candidates, 41 master's degree students, and 24 undergraduates. Combined with the $40+$ postdoctoral researchers associated with the project, the next generation of marine scientists is set to have a bright future.

\section{ACKNOWLEDGEMENTS}

The HERMES project is funded by the European Commission's Framework Six Programme (EC contract No GOCECT-2005-511234) under the priority "Sustainable development, global change and ecosystems." The Training-Through-

Research program is supported by the Intergovernmental Oceanographic Commission (IOC) of UNESCO. 尼 